\title{
SNAPSHOT A womb with a view
}

Opening up an unseen world, this detailed ultrasound scan captures an elephant not in the wild - but in the womb. The image, which has been enhanced with computer graphics, shows a 75-kilogram elephant fetus already decked out with footpads and a trunk.

To get close enough to the fetus to generate images, ultrasonographers donned shoulder-length gloves and gave the pregnant mother an enema - before inserting an ultrasound probe up the length of her rectum. This fetus has been gestating for nearly 19 months and would have started kicking and exercising its legs about 14 months earlier. It still has three months before it is to be born.

The picture was captured as part of a documentary called In The Womb, in which ultrasound images of dolphins and puppies as well as elephants were pieced together into short films, culminating in footage of their births. The show is to be broadcast next month on the National Geographic Channel in the United States and Europe, and on Channel 4 in Britain.

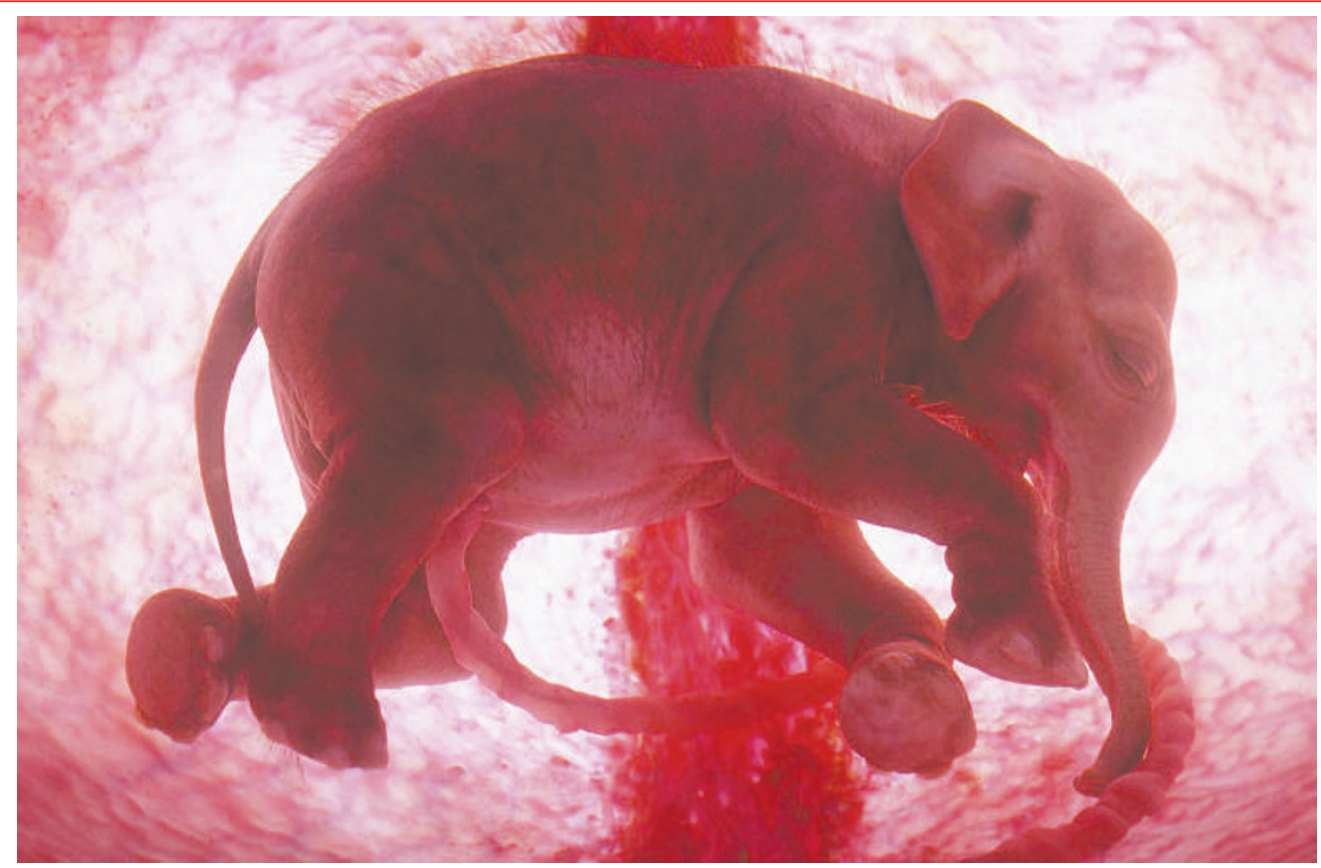

\section{Past drought hints at Africa's future}

An ecological survey of one of East Africa's worst-ever droughts provides a fresh look at how ecosystems respond to sudden, dramatic disturbances. The study documents a 19-year period in the late nineteenth century known to the native Masai people as Emutai - meaning 'to wipe out' - and it could help in determining how the landscape may respond to future climate shifts, as are predicted as a result of global warming.

In 1891, when the Austrian explorer Oscar Baumann travelled in Masailand in modernday Kenya, he was shocked to see "women wasted to skeletons from whose eyes the madness of starvation glared". Drought had first struck in 1883; the rains later failed completely in 1897 and 1898; rinderpest and bovine pneumonia destroyed herds. The Masai, who traditionally rely on animals for all of their food, were faced with famine and smallpox.

The latest research, published in the African Journal of Ecology $(44,458-467 ; 2006)$ reveals the ecological after-effects. "It was already in the history books - I was trying to calibrate the palaeoecological record against historical records," says Lindsey Gillson of the University of Cape
Town, who carried out the study at the University of Oxford's Environmental Change Unit.

She travelled to Kenya's Tsavo National Park to collect sediment, pollen and charcoal samples to determine the extent of the drought. The abundance of pollen from marginal wetland plants shows that lake shores were retreating during the event, and the increased presence of charcoal shows that spontaneous fires were common - all features of a major drought.

Gillson's results confirm that the Emutai was indeed a 'large infrequent disturbance' - the kind of climatic event, such as droughts, floods or hurricanes, that can leave a lasting impression on the land. And it's the kind of event that experts predict will become more common as global warming proceeds.

The work hints at the effects that can be expected if the region is hit by another drought of this severity. "What we need is a kind of probability - if we got a drought like this, will $\mathrm{x}, \mathrm{y}$ and $\mathrm{z}$ happen?" says Gillson. And now that she has identified the ecological signature of the drought, looking back through the palaeoecological record should help to show how often such extreme events are occurring and whether that frequency is changing over time.

But it will be crucial, Gillson adds, to link the ecological data more firmly with climate predictions, so that local people can be prepared
"African ecologists need to consider how to apply their skills and knowledge to the impact on humans of climate change." and adapt to these changes.

Helping Africans adapt to climate change is a priority, says Jon Lovett, an environmental researcher at the University of York, UK. "Given the close relationship between African livelihoods and ecology, African ecologists need to consider urgently how to apply their skills and knowledge to the impact on humans of climate change," he says.

That is especially true for the Masai. Development agencies are now urging them to diversify from their reliance on livestock and embrace staple crops. With three million Kenyans suffering from the current drought, the calls for a change of habits are growing louder.

Michael Hopkin 